\title{
Studies on Melanin
}

XXu. Nevus Fusco-caeruleus Acromio-deltoideus

\author{
By \\ Minor Itô \\ (伊 藤 瓚) \\ From the Department of Dermatology, Tohoku University, \\ Sendai; Director: Prof. M. It $\hat{o}$
}

(Received for publication, May 25, 1954)

The following case was described as the 18 th case of nevus spilus en nappe ${ }^{1}$ in my previous publication. Recently I had the opportunity to observe the biopsy of this patient. According to the quite coincidence of this histological findings to those of nevus fusco-caeruleus, the case here presented again is reported as a new type of nevus, namely nevus fusco-caeruleus acromio-deltoideus.

The patient, a girl, aged 17 noticed congenital pigmented macula on the area from left acromion to extensor surface of left upper arm. In the upper half of the macula diffused flecks thin blue in color were prominent and in the lower half portion its color tone decreased in grade and moreover many freckle-like spots were scattered over there. The pattern resembles one of a missprinted trichromatic illustration. The localization quite corresponded to the distribution of $\mathrm{Nn}$. supraclaviculares posteriores and $\mathrm{N}$. cutaneous brachii lateralis. No sensory disturbances were noticed. Slight gradial and chronometrical differences in local sweating than surroundings and the late development of erythema and wheal in histamine scratch test rather than normal skin were noticed. From these evidences local disturbances of vegetative nervous system were suggested. Histological findings quite same as Yoshida ${ }^{2}$ reported in nevus fusco-caeruleus ophthalmo-maxillaris Ota.

To summarize, the transition in distribution of the blue and brown flecks i.e. meso-and ectodermal origin respectively suggested the topographical difference in the peripheral course of nerve fiber and may be a datum which suspects the participation of nervous system in the melanin formation.

\section{References}

1) Itô \& Hamada, this journal, 1952, 55-Supplement, 44 (Plate $X$, Fig. 41).

2) Yoshida, ibid., 34 (Plate IV, Fig. 15, 16; Plate VIII, Fig. 31-33). 